\title{
Investigating the Effects of the Household Budget Survey Redesign on Consumption and Inequality Estimates: the Italian Experience
}

\author{
Nicoletta Pannuzi ${ }^{1}$, Donatella Grassi ${ }^{1}$, Achille Lemmi ${ }^{2}$, Alessandra Masi ${ }^{1}$, \\ and Andrea Regoli ${ }^{3}$
}

In 2014, many innovations were introduced in the Italian Household Budget Survey (HBS) in response to changes in European recommendations and purchasing behaviours and to an increased demand for information in the context of social and economic research. New instruments and techniques have been introduced, together with more accurate methodologies, with the aim of improving the survey, by both reducing the bias and variance of survey estimates and supplying estimation for additional subpopulations and variables. Given the parallel conduction of the former and new HBS in 2013, it has been possible to evaluate the effects of the abovementioned changes on consumption expenditure and inequality estimates and to compare the sample representativeness of selected subpopulations in both surveys.

Key words: Survey design; data quality; zero expenditures; post-stratification.

\section{Introduction}

Household Budget Surveys (HBS) are conducted in all EU member states and several other countries (OECD 2013); they mainly focus on consumption expenditure and have a primary aim (at the national level) of calculating weights for the Consumer Price Index. Since 1988, Eurostat has collected and disseminated these survey data every five years (Eurostat 2015).

In the most recent decades, a European (legally non-binding) agreement was made with the aim of developing shared definitions and methodologies to improve the quality and comparability of the HBSs. However, in the absence of a European framework regulation (Eurostat 2017, 2003), the national HBSs still differ in various aspects, ranging from methodologies to data collection techniques and definitions of variables.

1 Italian National Institute of Statistics, Via Cesare Balbo, 16-00184 Rome, Italy. Emails: nicoletta.pannuzi@istat.it, donatella.grassi@istat.it, and alessandra.masi@istat.it

2 ASEDS, Tuscan Interuniversity Research Centre "Camilo Dagum" University of Pisa, Department of Economics and Management, Via Cosimo Ridolfi, 10-56124 Pisa, Italy. Email: lemmiachille@virgilio.it

3 University of Naples Parthenope, Department of Management and Quantitative Studies, Via Generale Parisi, 13-80132 Naples, Italy. Email: andrea.regoli@uniparthenope.it

Acknowledgments: The Authors would like to express their gratitude to the members of the interinstitutional working group on poverty estimate - established in 2015 by the Italian National Institute of Statistics - for their valuable and constructive suggestions during the research work. The opinions expressed in this article solely represent those of the Authors and do not necessarily reflect the official viewpoint of the Italian National Institute of Statistics. 
In Italy, the survey has been conducted regularly since the 1960s; in 2014, it was completely redesigned (for details, see Grassi and Pannuzi 2015) to consider the new European recommendations and the changes in expenditure and consumption behaviours of the population. The purpose of the redesign was also to improve the survey, by reducing the variance of survey estimates and supplying estimation for additional subpopulations and variables.

Incorporating the European recommendations required change in both methodological issues and survey design relative to different aspects, including field of observation, sampling design and survey technique, and expenditure item classification.

The availability of new products in the market, the changes in the distribution channels and the important social, economic and cultural transformations of recent years (such as the increased foreign presence and changes in labour market participation) have modified the Italian dynamics of purchasing behaviours. This change has required new instruments, techniques and methods to properly collect consumption expenditure data.

All of these changes have entailed marked and statistically significant differences in many estimates produced by the survey (Istat 2015). Lemmi et al. (2019) analysed the differences between poverty estimates from the new and old surveys (hereafter new and former HBS), showing that the introduced innovations improved the estimation quality and determined a significant reduction in the number of households and individuals classified as poor.

In this article, we evaluate the effect of the redesign on the level, distribution and inequality of consumption expenditures and compare the sample coverage of selected subpopulations in both surveys. Specifically, we intend to show how the changes strive for variance reduction and demonstrate how the new design is successful in meeting this goal. In addition to the overall effect of the redesign, we also assess the impact of specific changes through an ad hoc simulation that treats the new HBS data as if they were observed according to the methodology of the former HBS. This investigation of the effects of the survey redesign was made possible by the parallel conducting of both surveys in the last two quarters of 2012 and all quarters of 2013.

Although the specific issues reported in this article relate to the Italian context and to 2013 data, it can be argued that this does not compromise its relevance or timeliness because the considered aspects have their own methodological relevance regardless of the country and data updating process. The applied approach can, in fact, represent a reference paradigm for evaluating the effects on estimates due to changes in different survey aspects.

The structure of the article is described as follows. Section 2 first summarises the main points of the HBS redesign process, highlighting the main differences between the former and new HBSs, and subsequently compares the coverage of selected populations and selected estimates between the two surveys. Section 3 analyses the effects of the innovations on the estimates of levels and inequality measures. Finally, the impact of the survey redesign on the estimates for population subgroups is presented in Section 4. Section 5 contains the conclusions.

\section{Former and New Italian Household Budget Surveys}

In this section, we compare the main characteristics of the former and new HBS. We also evaluate the coverage error in estimates for specific subgroups and the variance of the estimates of consumption expenditure levels and inequality. 


\subsection{Population and Sample Design Features}

For reasons related to survey costs and organisational issues, the samples of the former and new HBS are concentrated in a limited number (approximately 500) of the over 8,000 Italian municipalities. The consequent choice is a two-stage sample design, in which the first-stage units are the municipalities and the second stage units, or final sampling units, are the households.

In the former survey the municipalities were stratified, within each region, by demographic size only. In the new survey, the municipality typology is also inserted as a stratification variable distinguishing between metropolitan area (municipalities with over 250,000 inhabitants); large municipalities (municipalities in the periphery of the metropolitan area and municipalities with 50,000 inhabitants and more) and small municipalities (municipalities with less than 50,000 inhabitants). In these municipalities, the shares of the population are about $17 \%, 29 \%$ and $54 \%$, respectively. The stratification by municipality typology accounts for the different levels and styles of consumption expenditure associated with living in municipalities of different sizes and more or less close to metropolitan areas.

The choice of using a deeper stratification has the twofold aim of reducing the variance of the estimates and assuring sufficient data to produce estimates for specific subpopulations.

The HBS, in Italy, represents one of the primary sources for estimating the quarterly households' final consumption in the National Accounts System. The sampling design is therefore defined with reference to a generic quarter of the year and is identically replicated for the four quarters; moreover, a monthly stratification of the quarterly sample is also carried out. Consequently, the temporal dimension can be considered an additional stratification variable of the sample, which allows taking into account the highly seasonal nature of some types of expenditure.

Besides, the municipality typology and the month of participation are also considered in calculating the weights used to expand the sample to the population. They are obtained as the product of the following three factors: (1) basic coefficient (reciprocal of the inclusion probability); (2) correction factor for nonresponse (inverse of the response rate); (3) correction factor to match known population totals.

The post-stratification adjustments to the following control totals used in the former HBS have been preserved in the new survey:

- Resident population by geographical area (North, Centre, South and Islands), sex and age groups $(0-14,15-29,30-44,45-59,60-74,75$ or more), in order to take into account the different levels and composition of expenditure characterising individuals of different age and sex, but also people living in the southern or northern part of the country. Traditionally about $46 \%$ of the total population live in the North, where households present higher levels and different typologies of expenditures than in the Centre and the South, where the share of the population is approximately $20 \%$ and $34 \%$, respectively, and

- Resident population and households by region, following the NUTS2 Eurostat classification, in order to account for any differences in terms of administrative rules and services availability which may have impact on consumptions expenditures of citizens. 
To these, others post-stratification adjustments have been added in the new HBS:

- Resident population and households by geographical area and municipality typology (metropolitan area, large municipalities, small municipalities), to be consistent with the sample stratification,

- Foreign population by geographical area and sex to account for the growing size of the foreign population in the total resident population - in 2014 it represented almost $8 \%$ of the resident population - and their different habits and consumption levels,

- Population of 15 years and over by geographical area, employment status and position (manager/white collar, blue collar, entrepreneur/freelancer, self-employed, looking for a job, retired from work, other), considering that the condition and the professional position impact on the income levels, and therefore on the expenditure, of the population; this total is derived from the Istat Labour Force survey, and

- Population and households by geographical area and participation month to be consistent with the sample stratification.

\subsection{Comparison of the Main Survey Characteristics}

In addition to the sample issues mentioned in the above sub-section, other HBS differences are summarised in Table 1. Both surveys are conducted using face to face interviews (just one interview in the former HBS, two interviews in the new HBS) and diaries (two diaries in the former HBS, one diary in the new HBS).

The adoption of the 2013 COICOP classification of variables (UN Statistical Commission 2018) was one of the Eurostat recommendations (Eurostat 2013) intended to achieve better comparability of measurement among the HBSs of different countries and with the consumer price indices classification. This change has resulted in an increase in expenditure items from 265 to 482 items.

Also part of the change was replacing the single questionnaire with two questionnaires (Zezza et al. 2017; Ngandu et al. 2016; Angrisani et al. 2015; Barrett et al. 2015; Bee et al. 2015; Smith et al. 2014; Andreski et al. 2014). The two new questionnaires are administered through computer-assisted personal interviews (CAPI) rather than through the paper-and-pencil interviews (PAPI) used previously. One of the two questionnaires collects information on socio-demographic characteristics of household members and housing characteristics (that are invariant in the short term); the other collects less frequent or exceptional expenses for a predefined list of items (with empty spaces to be filled for unlisted items). The self-administered diary, as in the former HBS, is a paper diary used to collect daily or high-frequency expenditures; also in this case the items are predefined and listed, with the opportunity of adding new ones. Instead of collection through a separate diary, as in the former survey, in the new HBS, self-consumption is collected in a dedicated section of the daily expenditure diary following the COICOP classification. The diaries are collected by an interviewer who converts them to electronic format using a computer-assisted input (CADI) system.

In both surveys, substitutions to replace nonresponding households are allowed (for details, see Freguja and Romano 2014). Nevertheless, in the new HBS both the computerassisted interviewing and the availability of the list of residents from the municipality 


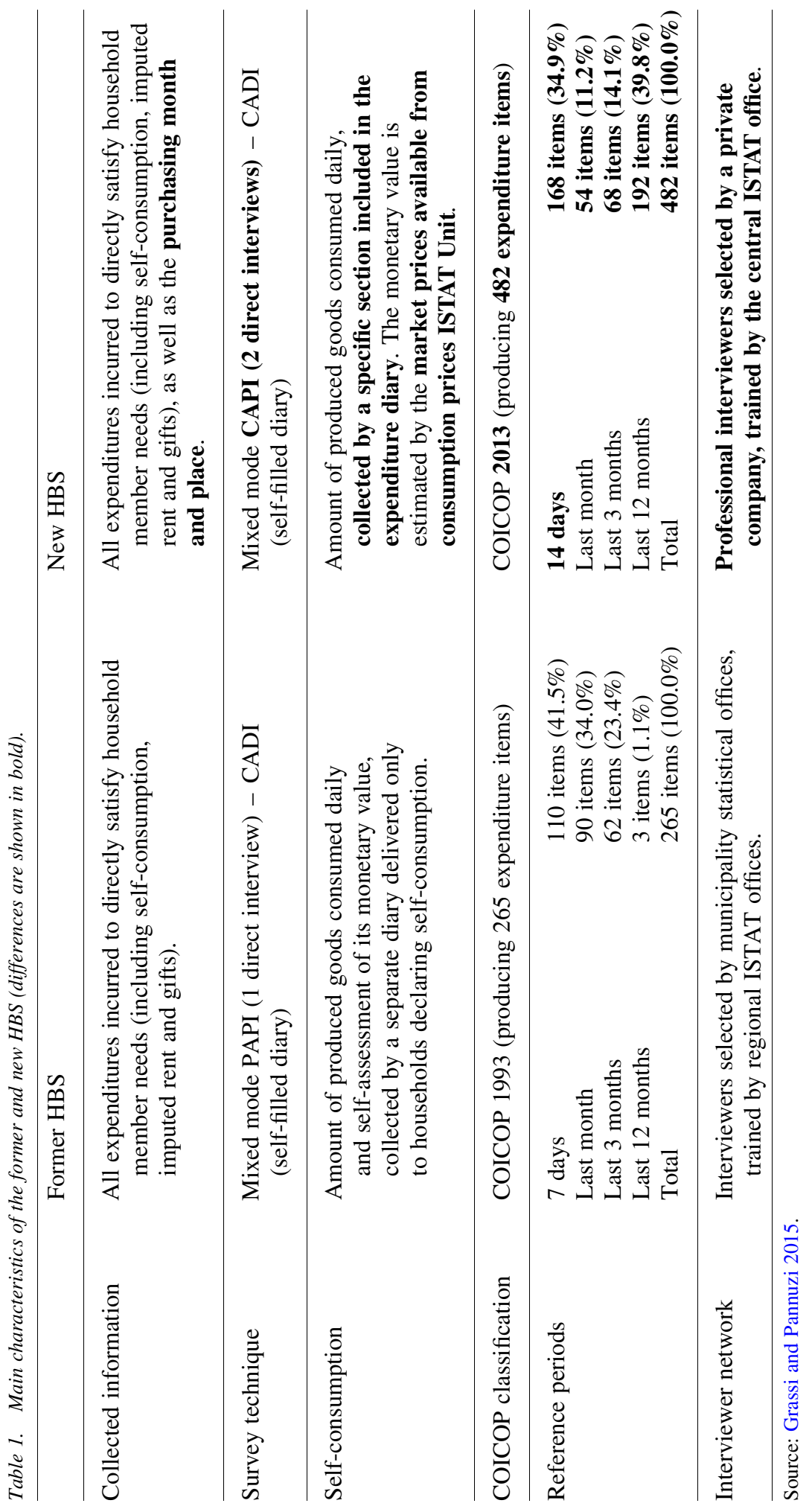


register offices allow the substitution rules to be stricter than in the former HBS, which should result in the substitute household being more like the nonresponding household.

For each listed item, in addition to collecting all expenditures incurred by the household members to directly satisfy their needs, the new HBS collects information on: (1) expenditure occurrence; (2) purchasing month; and (3) purchasing location. The first information - about whether or not a given expenditure has been made - makes it possible to distinguish between missing expenditures due to undeclared amounts (to be imputed) and actually null expenditures.

In general, the expenditure reference periods in the new HBS are longer than in the former HBS. Moreover, the percentage of expenditures collected for the previous month has decreased from $34 \%$ to $11.2 \%$, and the percentage of expenditures collected for the previous 12 months has increased from $1.1 \%$ to $39.8 \%$.

Finally, expenditures for 43 new items, referring to goods and services recently introduced into the market, have been added in the questionnaire. For example, the new items include expenditures for drones or satellite navigators, e-books and e-readers, private security services, or rental of furniture.

\subsection{Coverage of Selected Subpopulations}

With the aim of evaluating the coverage of selected subpopulations in both surveys, the final and unweighted estimates of the proportions of certain subgroups in both HBSs are compared with the same proportions in the resident population (Table 2). These population subgroups are those involved in the new HBS additional post-stratification procedure, therefore the relative standard errors for the new HBS final estimates are not reported because they are, by definition, equal to 0 . These results complement the information already discussed in Lemmi et al. (2019), which proved the better coverage of households by economic condition in the new HBS (compared with the former HBS).

If we consider citizenship, the estimated proportion of foreign people in the former HBS $(5.3 \%)$ is significantly lower than the proportion in the population (7.8\%) (Table 2 panel a, Total population). Moreover, the unweighted estimate (based on the achieved sample) in the new HBS (5.4\%) is also closer to the population proportion than the estimates in the former HBS (4.7\%). Similar results are observed for the population estimates by employment/professional status. As an example, with reference to managers and white collar employees, compared with the population proportion equal to $14.5 \%$, the unweighted estimated proportions in the former HBS and in the new HBS are $16.9 \%$ and $15.9 \%$, respectively, whereas the final estimated proportion in the former HBS is $17.3 \%$ (Table 2 - total population estimates).

At the household level, the final estimates show how the households living in the largest municipalities are well covered in both surveys. In terms of unweighted estimates, the new HBS estimates are again closer to the population proportions than the former HBS estimates. The final estimates in the former HBS over-represent the households living in small municipalities and under-represent those living in metropolitan area suburbs and municipalities with more than 50,000 inhabitants (Table 2, panel b, Total households).

These findings confirmed the non-negligible gain of introducing tighter requirements for substitutions and extra post-stratification adjustments to survey control totals in the new survey. 


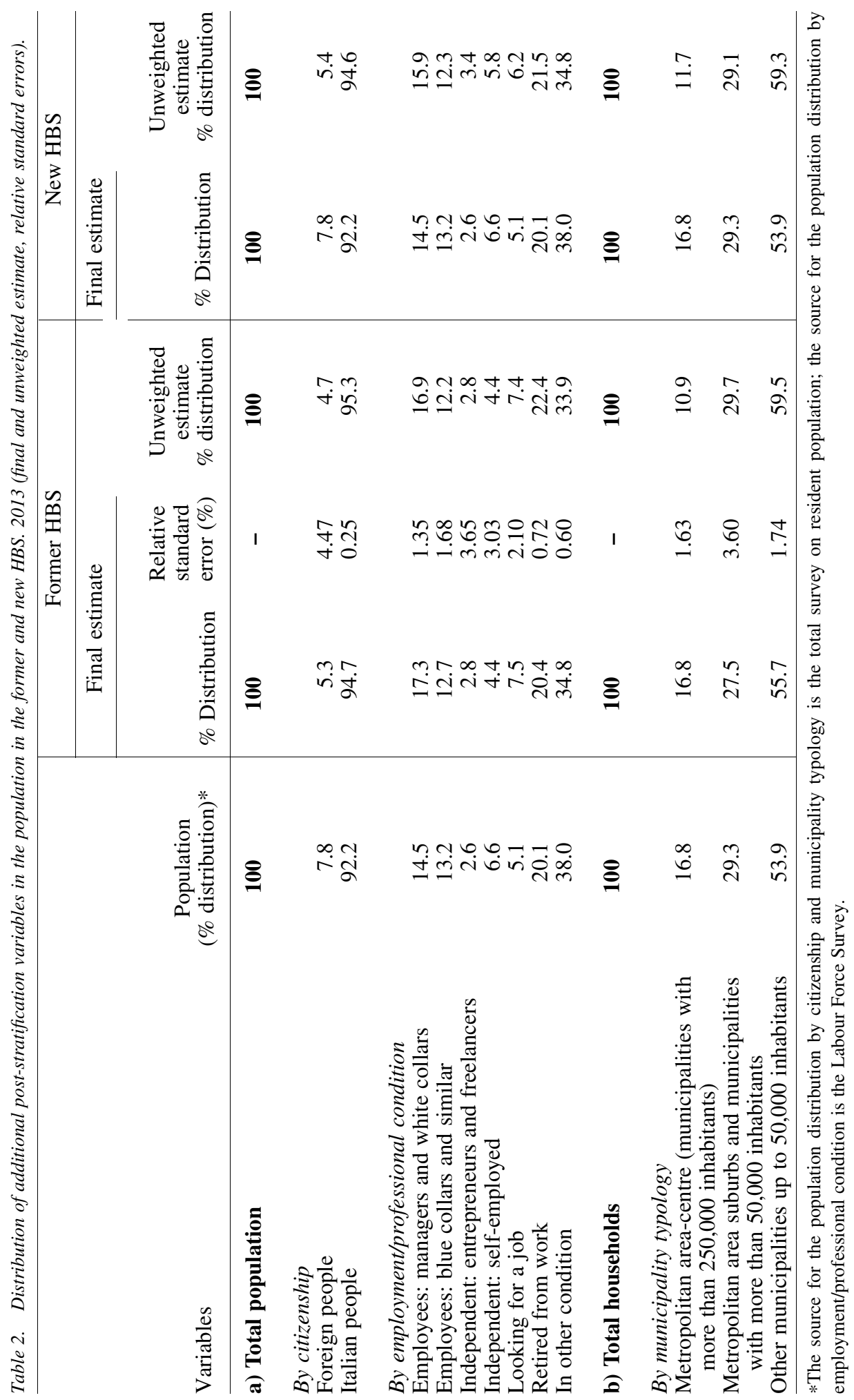




\subsection{Comparison of Selected Estimates}

The survey redesign produced higher consumption expenditure levels together with a smaller range of inequality in the new HBS than in the former HBS. For both surveys, Table 3 shows the estimates of the average consumption expenditure, the deciles of the distribution and the inequality measures (Gini index and income quintile share ratio S80/S20) together with their relative standard errors and $95 \%$ confidence intervals calculated on the total expenditure in equivalent terms. The equivalent household consumption expenditure allows comparisons of households with different size or composition. It is obtained using an equivalence scale constituted by a set of coefficients accounting for the economies of scale that can be realised as the household composition changes; the equivalence scale used in this article is known as the Carbonaro scale (Commissione di indagine sulla povertà e sull'emarginazione 1996).

Although the new HBS has a markedly smaller achieved sample size than the former HBS (61\% versus $74 \%$ of the selected sample), the sampling errors associated with the new HBS estimates are lower than those associated with the former HBS estimates. Moreover, the differences between the estimates obtained by the surveys are statistically significant.

In particular, the difference in the average monthly household consumption expenditure between the two surveys is significantly different from zero and is equal to $3.1 \%$.

The consumption expenditure estimates obtained using the new HBS are higher in value than those obtained using the former HBS along the entire consumption expenditure distribution. The differences are statistically significant for each decile of the equivalent distribution, although they are more marked in the bottom portion of the distribution (for the first two deciles the differences are $13 \%$ and $9.8 \%$, respectively). The higher increase in the bottom part of the distribution entails a significantly lower inequality of the consumption expenditure distribution in the new HBS than in the former HBS. The value of the Gini index changes from 0.327 (former HBS) to 0.304 (new HBS), whereas the quintile share ratio - S80/S20 - changes from 5.4 to 4.8 (Table 3).

\section{Effect of Single Innovations on Estimates}

In this section, we evaluate the effect of each innovation introduced in the new HBS on estimates of levels and inequality. We are interested in isolating the effects of single changes because they might cancel each other out when the global effect is considered. In certain cases, our findings simply confirm what is already contained in the specific literature, whereas in other cases, the evidence might represent new elements to be considered when HBSs or households sample surveys in general must be redesigned. As advised by the relevant literature (Van den Brakel et al. 2017; Gazzelloni 2006; Zbikowski and Lubich 2006; Polivka and Miller 1998), the HBS redesign process was preceded by a series of experimental surveys (Grassi and Pannuzi 2015). Furthermore, the former and new HBSs were conducted in parallel during the last two quarters of 2012 and all quarters of 2013. To assess the effects of innovations on the estimates, we have conducted a detailed ad hoc simulation. 


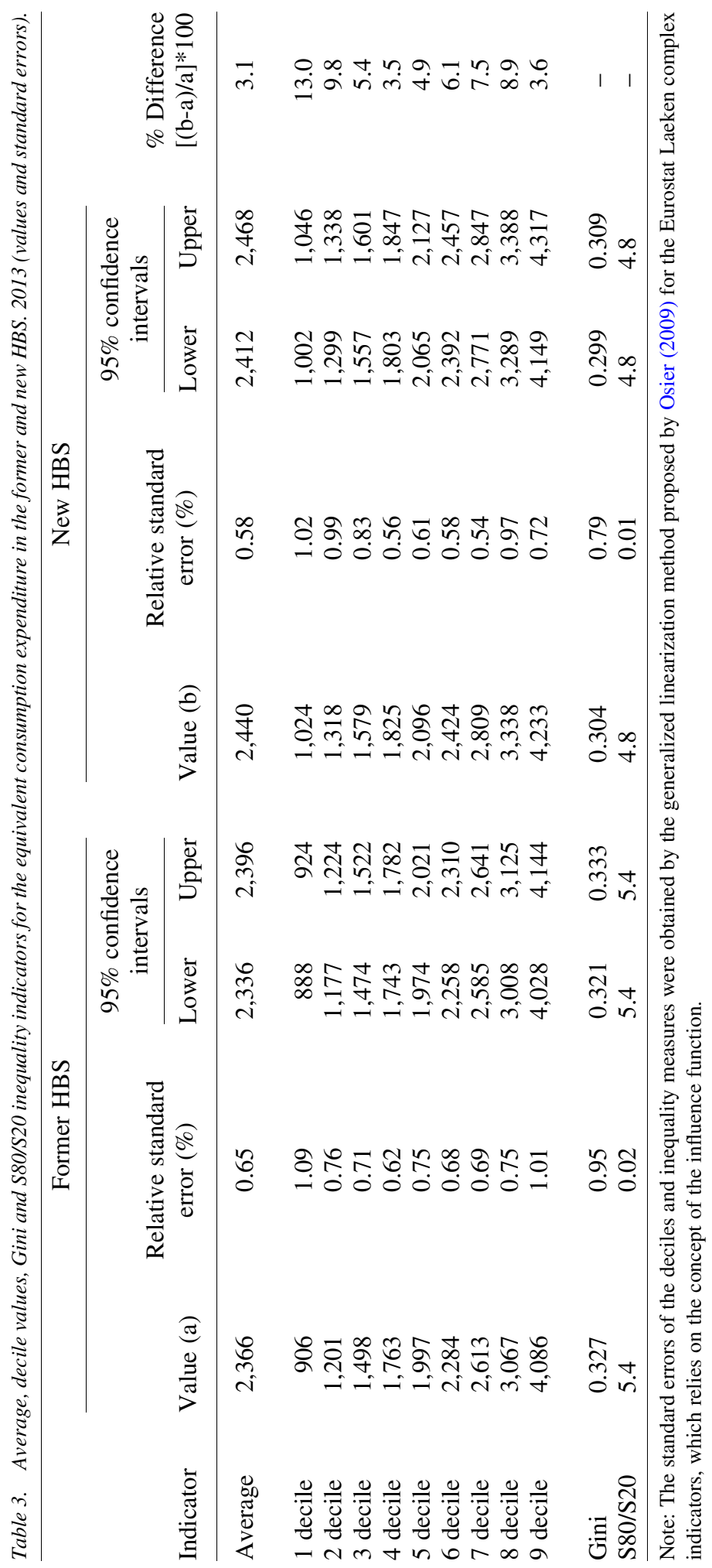


Starting from the data of the new HBS, we performed the following steps:

1. we considered for each item only the expenditures made in the portion of the reference period overlapping the former HBS reference period,

2. we disregarded all the imputed expenditures due to undeclared amount,

3. we aggregated the expenditures referring to items that have been split in the new HBS (3.1) and we ignored the expenditures for new items that were not included in the former HBS (3.2), and

4. we recalculated the weights without the post-stratification adjustments to survey control totals introduced in the new HBS.

We first comment on the findings with reference to the estimate of the average consumption expenditure (Table 4). For step (1), because the reference periods in the new HBS are generally larger than in the former HBS, we recalculated the average consumption expenditure on the new HBS data for each item obtained by considering only the expenditures afforded during the reference period used in the former HBS for the same item. For example, in the former HBS, the expenditures for domestic services were collected with reference to the last month, whereas in the new HBS they are collected with reference to the last three months. For our purposes, we recalculated the average monthly expenditures on new HBS data by considering only the expenditures for domestic services made in the last month. This recalculation was possible due to the information

Table 4. Simulation of the redesign effects on average consumption expenditure. 2013 (values in euros and percentage variation).

Data source

$\begin{array}{cc}\text { Average } & \\ \text { equivalent } & \% \text { Variation to } \\ \text { consumption } & \text { the previous } \\ \text { expenditure } & \text { value }\end{array}$

Former HBS

2,366

New HBS

2,440

3.1

1. New HBS with the former HBS

2,469

reference periods

2. New HBS with the former HBS

reference periods and without

imputed expenditures

3.1 New HBS with the former HBS

reference periods, without imputed

expenditures and without the splitting effect

3.2 New HBS with the former HBS

reference periods, without imputed

expenditures, without the splitting effect

and without the new items

4. New HBS with the former HBS reference

periods, without imputed expenditures,

without splitting effect, without the new items and without new post-stratification constraints (new HBS "treated to simulate" the

former HBS methodology) 
on the purchasing month collected in the new HBS. By applying this process for all items, the average monthly consumption expenditure increases from EUR 2,440 to EUR 2,469 , which corresponds to a change of $+1.2 \%$. In other words, using longer reference periods results in lower average consumption expenditure estimates. This result could be due to the "memory recall error", namely, that households tend to forget expenditures as the length of the reference period increases. Nevertheless, in the new HBS, this effect has been kept under control by adopting specific strategies, as indicated in the literature (Mulry et al. 2016; Mathiowetz et al. 2002; Neter and Waksberg 1964). In particular, in addition to precise anchoring of the time frame and precise definitions, we introduced an easier-to-answer set of questions related to the event of interest ("warm-up" questions), referring to whether the expenditure was made, in which month it was made, and the purchasing place. From the answers to the "warm up" questions, we have also been able to impute the missing expenditures. The expenditures, similarly to other quantitative variables, are treated by IVEware software (developed by the Survey Research Center, Institute for Social Research, University of Michigan), which makes single or multiple imputation by model using the sequential regressions method (Raghunathan et al. 2001) and Banff software (developed by Statistics Canada), based on Fellegi-Holt methodology through the Nearest-Neighbor Donor method (see Grassi and Pannuzi 2015).

For our ad hoc simulation, with reference to step 2, we recalculated the average consumption expenditure on the data from the previous step without considering the imputed expenditures, and the value changes from EUR 2,469 to EUR 2,421 (-1.9\%). This result suggests that using expenditure-related (easy to answer) questions (as in the new HBS) allows us to distinguish between a missing expenditure and actually null expenditure, and in this manner, imputation can be used to recover missing values and complete the estimated consumption expenditure (Gonzalez and Eltinge 2010).

Step 3 includes the effect of splitting items (3.1) and the effect due to the introduction of new items (3.2). For the former point, because the COICOP version adopted in the new HBS is more detailed than that used in the former HBS, for the data from step 2, we aggregated items and summed all of the related expenditures to reproduce the same classification used in the former HBS. To give an example, the aggregate "Bread, breadsticks and crackers", which corresponds to a single item in the former HBS, is obtained by summing two items in the new HBS: "Bread" and "Breadsticks and crackers". By comparing the expenditure referred to these aggregates, we can estimate the effect of the item splitting. The consumption expenditure changes from EUR 2,421 to EUR 2,361. This result is consistent with what is already known in the literature (Crossley and Winter 2015), that a greater disaggregation of items induces higher estimates of the total expenditure, presumably because it helps households to remember expenses that could otherwise be forgotten (Cifaldi and Neri 2013).

The periodic updating of the COICOP classification also has the aim of following the change in goods and services available in the market by eliminating those that are no longer sold and introducing novelties instead. To assess the effect of the introduction of new items (step 3.2), we exclude the expenditures referred to new items from the data coming from step 3.1. This simulation obviously produces a reduction of the monthly expenditure, specifically from EUR 2,361 to EUR 2,244 (-5.0\%). 
Finally, (step 4), because additional post-stratification adjustments have been added in the weighting system in the new HBS, we recalculated the weights without the new poststratification adjustments (in a similar manner as in the former HBS). The consumption expenditure calculated using data from step 3.2 and the weights without the poststratification adjustments increases from EUR 2,244 to EUR 2,341 (+4.3\%). This effect is strictly linked to the nature of the variables used in post-stratification. In our case, the new adjustments give more weight to subgroups of the population with low levels of consumption expenditure (foreign people in particular). As already known in the literature, introducing adjustments in the final weight calculation allows us to improve the accuracy of the estimates, and the more the auxiliary variables considered are associated with the variables under investigation, the more the distortion of the estimates is reduced (Lavalle and Beaumont 2015).

The last estimate (point 4 of Table 4) represents the final result of the simulation, and specifically, it is the average consumption expenditure from the new HBS "treated to simulate" the former HBS methodology according to the above-described sequence of steps. Considering the associated relative standard errors (equal to $0.76 \%$ for the new HBS "treated to simulate" the former $H B S$ ), it is statistically identical to the estimated average based on the former HBS data.

The simulation of the redesign effect on inequality measures along the abovementioned steps 1 to 4 (Table 5) shows that the introduction of new items is the only innovation that produces an increase in inequality, whereas the other innovations tend to reduce the degree of inequality. This result appears to be linked to the fact that the new items refer to expenditures for goods and services that are more likely afforded by households/people with high levels of consumption. However, in terms of inequality, the estimates calculated

Table 5. Simulation of the redesign effects on inequality indices. 2013.

\begin{tabular}{|c|c|c|}
\hline Data source & $\begin{array}{l}\text { Inequality index } \\
\quad(\mathrm{S} 80 / \mathrm{S} 20)\end{array}$ & $\begin{array}{l}\text { Gini } \\
\text { index }\end{array}$ \\
\hline Former HBS & 5.4 & 0.327 \\
\hline New HBS & 4.8 & 0.304 \\
\hline $\begin{array}{l}\text { 1. New HBS with the former HBS } \\
\text { reference periods }\end{array}$ & 5.2 & 0.324 \\
\hline $\begin{array}{l}\text { 2. New HBS with the former HBS } \\
\text { reference periods and without } \\
\text { imputed expenditures }\end{array}$ & 5.4 & 0.330 \\
\hline $\begin{array}{l}\text { 3.1 New HBS with the former HBS } \\
\text { reference periods, without imputed } \\
\text { expenditures and without the splitting effect }\end{array}$ & 5.4 & 0.333 \\
\hline $\begin{array}{l}3.2 \text { New HBS with the former HBS } \\
\text { reference periods, without imputed expenditures, } \\
\text { without the splitting effect and without the new items }\end{array}$ & 5.2 & 0.329 \\
\hline $\begin{array}{l}\text { 4. New HBS with the former HBS reference periods, } \\
\text { without imputed expenditures, without splitting effect, } \\
\text { without the new items and without new } \\
\text { post-stratification constraints (new HBS } \\
\text { "treated to simulate" the former HBS methodology) }\end{array}$ & 5.5 & 0.334 \\
\hline
\end{tabular}




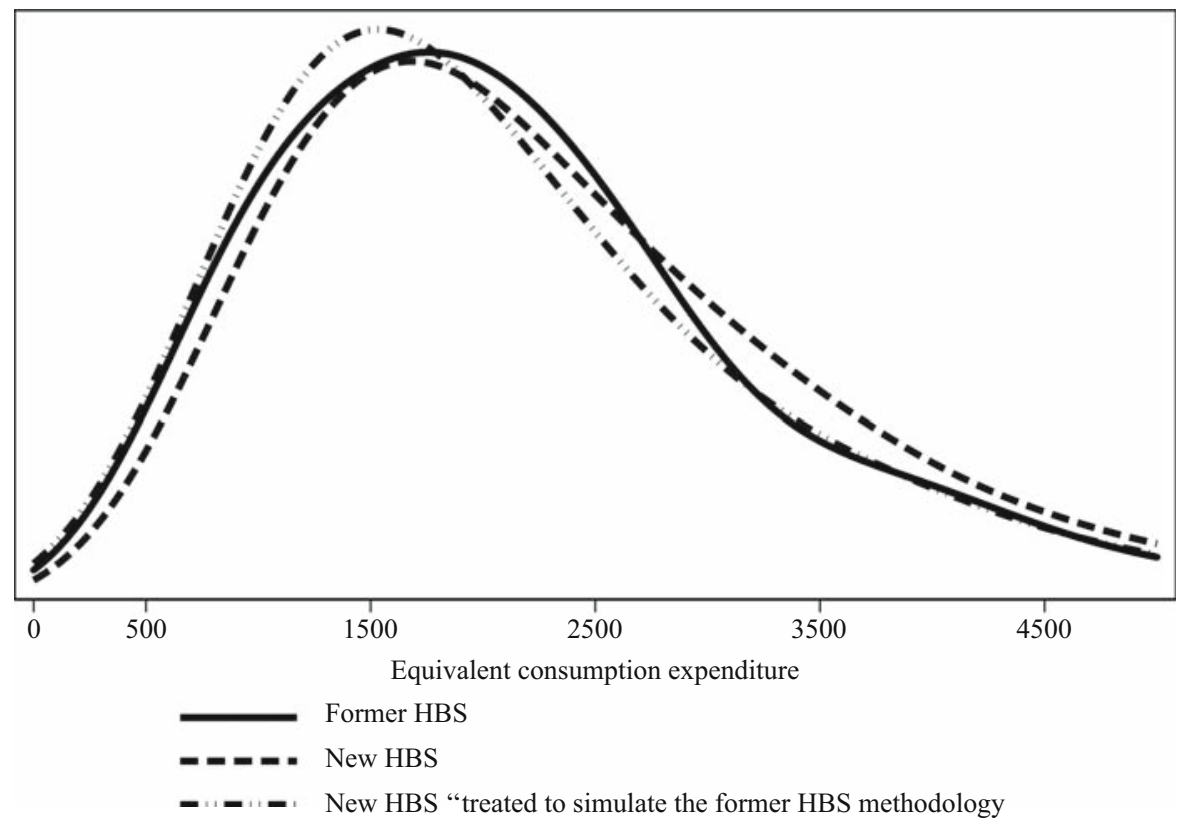

Fig. 1. Kernel density estimation of the equivalent consumption expenditure distribution in the former HBS, new HBS and new HBS "treated to simulate" the former HBS methodology. 2013.

on the new HBS "treated to simulate" the former HBS data are also closer to those resulting from the former HBS data than to those obtained on new HBS data.

The "simulation" in Table 5 does not presume to reproduce the former HBS data via the new HBS data. Indeed, several sources of difference have not been included in the simulation; for example, the effect of the survey technique change from PAPI to CAPI or of the interviewer network change from public to private/professional. Nevertheless, even if the distributions are different (this is confirmed by the Kolmogorov-Smirnov and Kuiper tests, which, however, tend to be rather conservative with large samples), it is undeniable that the equivalent consumption expenditure distribution on data from the former HBS is more similar to that obtained on data from the new HBS "treated to simulate" the former $H B S$ than that obtained on data from the new HBS, especially if considering the distribution tails (Figure 1).

\section{Association Between Household Characteristics and Consumption Expenditure Level}

This section investigates whether the new HBS redesign has modified the consumption expenditure level estimates in a different way for different household subgroups.

Table 6 (see Appendix, Section 6) reports the household percentage composition, the average equivalent consumption expenditure and its relative standard error (including the $95 \%$ confidence intervals) for selected subgroups of households from both surveys. The last column contains the estimated percentage difference with assessment of its significance via the two-sample t-test. The average consumption estimate in the new HBS is significantly higher than in the former HBS for (1) households living in either the Centre 
or South and Islands, (2) municipalities in metropolitan area (both centre or suburbs) and with at least 50,000 inhabitants, (3) households with at least two members, (4) households with no minor children, (5) households with elderly members, (6) households headed by a retired person or by an employee in non-manual jobs, or (7) households without selfconsumption. The largest differences (slightly less than 10\%) are observed for households with at least four members and for those living in metropolitan area centres. No subgroup of households exhibits a significantly higher average consumption expenditure in the former HBS than in the new HBS.

The consumption expenditure levels are linked with both the expenditure amount and expenditure frequency, which in turn are strongly associated with household size. The enlargement of the reference periods, as well as the imputation of expenditures and the introduction of new items in the new HBS has produced an increase in the reported number of expenditure events. Figure 2 shows that this increase is more pronounced for larger households $(28 \%$ for households with four or more members versus $21 \%$ among single persons).

As a consequence, in the new HBS compared with the old HBS, we observe an increase in the share of small households and a reduction of the share of large households in the bottom fifth of the distribution. Moreover, this effect is more evident among households in the South and Islands and households in the largest municipalities (Figure 3).

This evidence appears to be justified by the changing purchasing behaviours. In recent decades, households have reduced the time spent shopping and have made less frequent shopping trips. The opportunities to purchase larger quantities of goods at lower unit prices or to benefit from discounted prices encourage households to buy goods in bulk and to stock up in ways that were not feasible in the past (Censis 2012).

It is clear that this behaviour more frequently belongs to large households (those able to buy and consume larger quantities of goods), households in metropolitan areas (where the mobility costs are higher than in smaller municipalities) or in the South and Islands (where households more often have stricter budget constraints that might impose saving strategies) (Bank of Italy 2018).

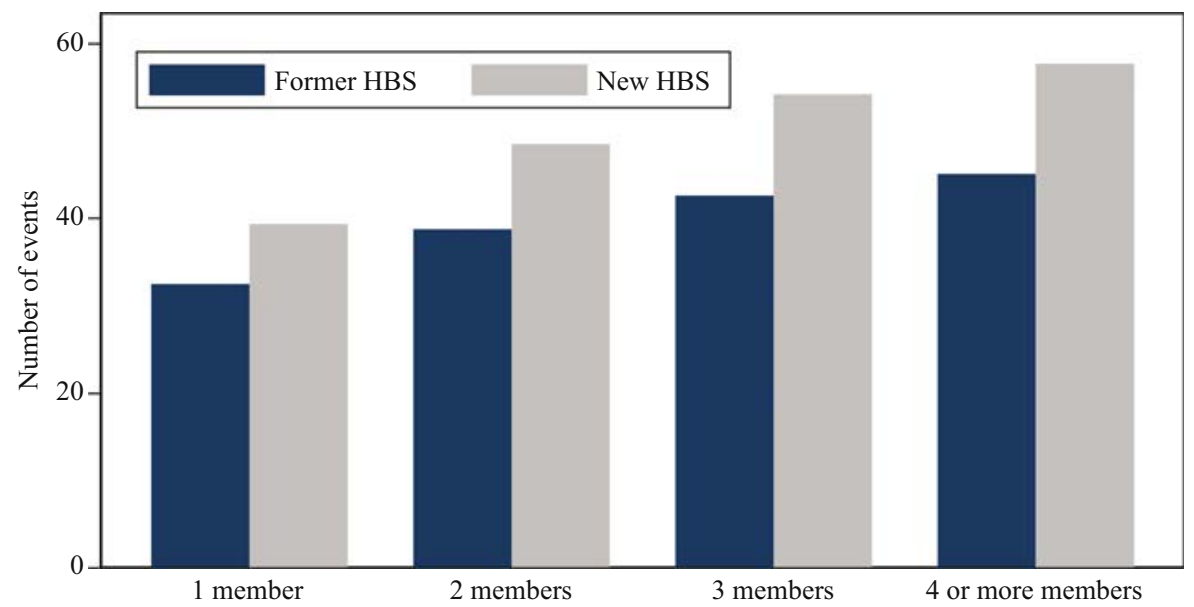

Fig. 2. Average number of expenditure events by household size in the former and new HBS. 2013. 


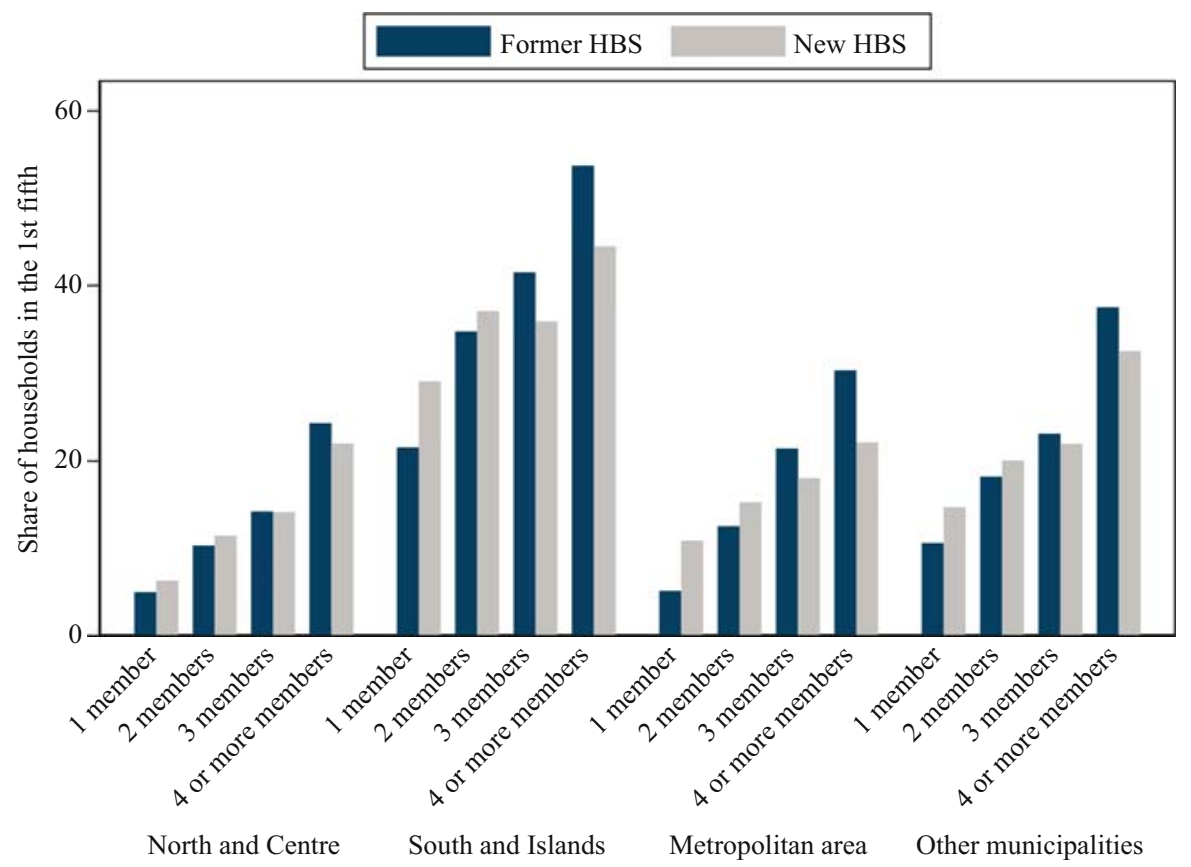

Fig. 3. Share of households in the first fifth of the equivalent consumption expenditure distribution by household size and geographical area and by household size and municipality typology in the former and new HBS. 2013.

Moreover, the self-consumption collection mode in the new HBS also produces a higher impact on estimates for households in the South and on Islands than elsewhere. Comparing the former and the new HBS, the share of households with self-consumption in both surveys remains nearly the same in the North (around 6.2\%), doubles in the Centre (reaching $8.7 \%$ ) and nearly triples in the South and on the Islands, where the share exceeds $10.3 \%$ in the new HBS.

Finally, to supply evidence of the main determinants of consumption expenditure levels in both surveys, regression models have been estimated.

The dependent variable is defined by taking logarithmic transformation of the consumption expenditures. The covariates are the following household characteristics, all entered as binary (0/1) variables: geographical area, household size, presence of elderly or minor members, municipality typology, occupational/professional status of the household head, and presence of self-consumption. Using the logarithmic transformation of the dependent variable, the estimated coefficient associated with a given category of the binary predictor approximates the relative gap in the average consumption expenditure with respect to the reference category when the other covariates are held constant.

The linear regression model estimates (Appendix, Table 7) show how the consumption levels are higher in both surveys for households living in the North, in a metropolitan area centre, with five or more members, without minor or elderly members, or headed by an employer or professional. However, the lowest levels are registered for households living in the South, in small municipalities, with only one member or headed by someone looking for a job. In the new HBS, households with self-consumption exhibit a significantly higher level of consumption compared with households with the same characteristics not 
reporting self-consumption. In the former HBS, this effect is not significant. This result is linked to the different way of collecting self-consumption in the new HBS, which increased the share of households with self-consumption. If we analyse the results of the quantile regression (Table 7 in Appendix reports the estimates for the 25th, 50th and 75th percentiles), we can confirm that along the entire distribution, the consumption levels are higher for households living in the North, in the largest municipalities, without minor children or elderly members, or headed by an employer or professional. Generally, the highest levels of consumption for large households are also confirmed for the new HBS and especially in the bottom portion of the distribution, even if the difference between households with four and households with five or more members is not statistically significant. As previously noted for the linear model, in the new HBS, households with self-consumption have a higher level of expenditure than the other households.

\section{Conclusions}

Controlling all of the possible sources of errors is a crucial aspect for survey design or renewal. In particular, in this article, we assessed the effect of the innovations introduced in the new Italian HBS, and we found that the new survey produced estimates closer to those obtained by external sources with smaller sample errors in comparison with the former HBS.

Specifically, despite a smaller achieved sample size, the new survey design has succeeded in reducing the variance of the average, the vast majority of the deciles and the inequality measures of the equivalent consumption expenditure. The decrease in variance is especially strong for estimates of the average consumption expenditure by municipality typology, which has become a new domain for stratification of the units at the first stage in the new HBS. We also showed a non-negligible gain in terms of coverage error reduction due to extra post-stratification adjustments to citizenship and professional condition of the population and to the typology of household municipality of residence, together with tighter requirements for substitutions to replace nonresponding households.

As the result of all of the changes introduced in the transition from the former survey to the new survey, the overall effect is that the new HBS exhibits higher levels of consumption expenditure, especially in the bottom portion of the distribution, and a lower inequality degree. These differences are all statistically significant.

The main novelty of the article lies in investigation of the effects of changes in specific aspects of the survey, which are usually less addressed in the literature. Indeed, the effect of survey redesign has been deeply studied in the specific literature, primarily with reference to such aspects as survey technique and interviewer effect, to name a few. Conducting the surveys in parallel enabled separate quantification of the impact due to the enlargement of the reference period for the expenditures, the imputation of zero expenditures, the splitting of expenditure items, the introduction of new items and the addition of post-stratification adjustments. We found that changes in these aspects have a non-negligible effect on the final estimates.

In particular, the results show how imputing zero expenditures, splitting items of consumption and introducing new items combine to produce an increase in the estimated consumption expenditure levels, as expected. Moreover, the increase due to all of these 
changes more than compensates for the decrease in the consumption expenditure due to the introduction of post-stratification adjustments and the extension of reference periods.

With reference to the effects of the redesign on the inequality measures, we found that the introduction of new expenditure items is the only inequality-enhancing change, whereas every other change tends to reduce the inequality degree. The sign of this effect depends on which subgroups of population are primarily involved in the purchase of the new goods or services. In the Italian HBS, the expenditures for new items occur mainly in households with a high level of consumption expenditure, which explains the increase in inequality.

The effect of the introduction of new post-stratification depends on which subgroups of the population are better represented after weighting. In the Italian HBS, the weight system increases the share of population with a low level of consumption, producing a decrease in both level and inequality of consumption expenditure.

The enlargement of the reference periods allows both a better approximation of the household consumption expenditure and an increase in the probability of capturing the expenditure event, thus reducing the proportion of households with no expenditures and, therefore, the variability of the estimates. Nevertheless, larger periods might give rise to strong memory recall errors; therefore, it is crucial to use strategies to control or reduce them.

Although the difference between the population average consumption expenditure in the former and new HBS does not appear to be remarkable, even if statistically significant, it is particularly marked for large households, those living in the South or on Islands, or in metropolitan areas, with a relevant impact on variability and inequality. Moreover, the new HBS is also able to capture the effect of self-consumption, given the better instrument used to collect the information, which increased the number of households with selfconsumption. 


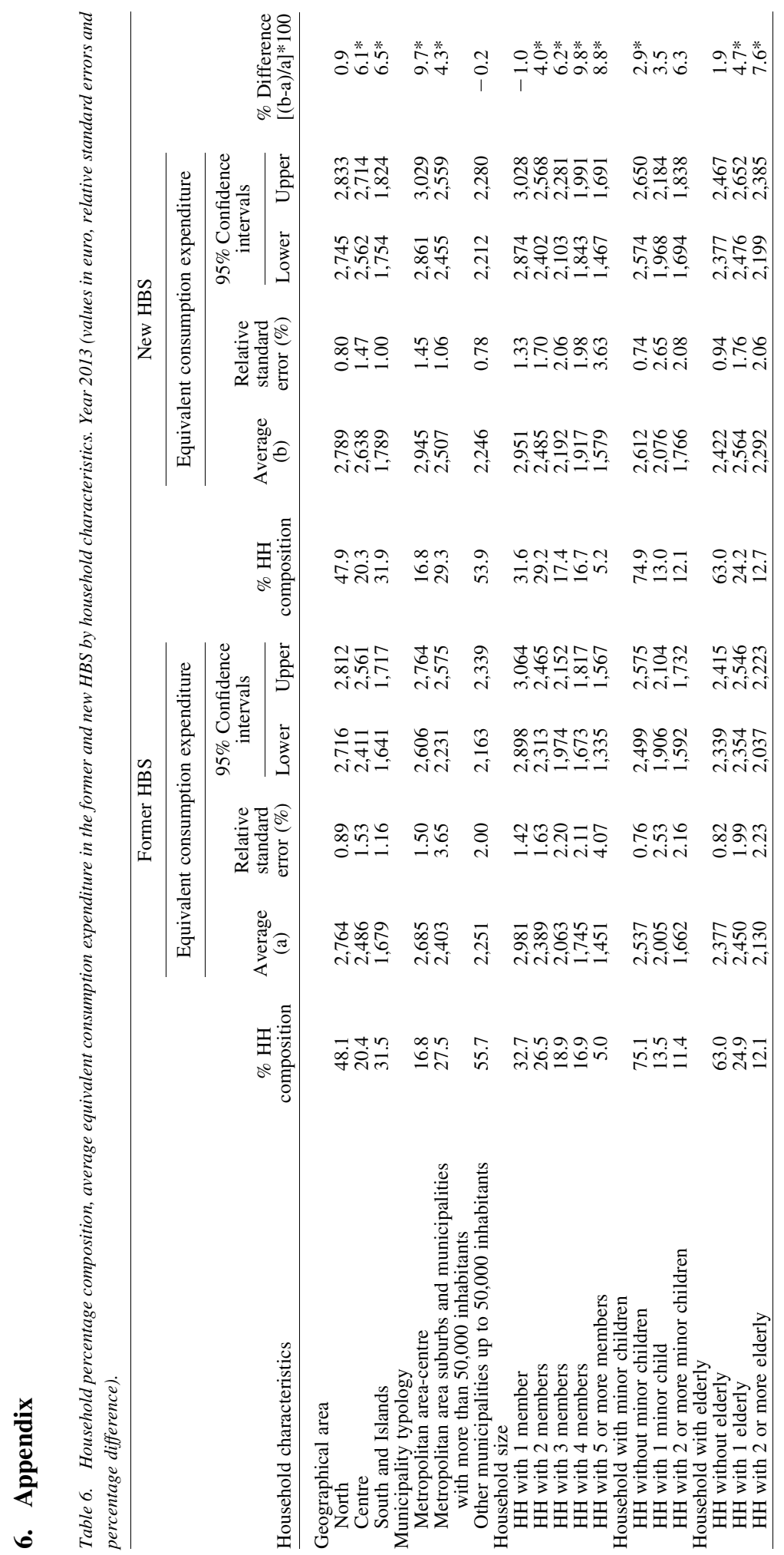




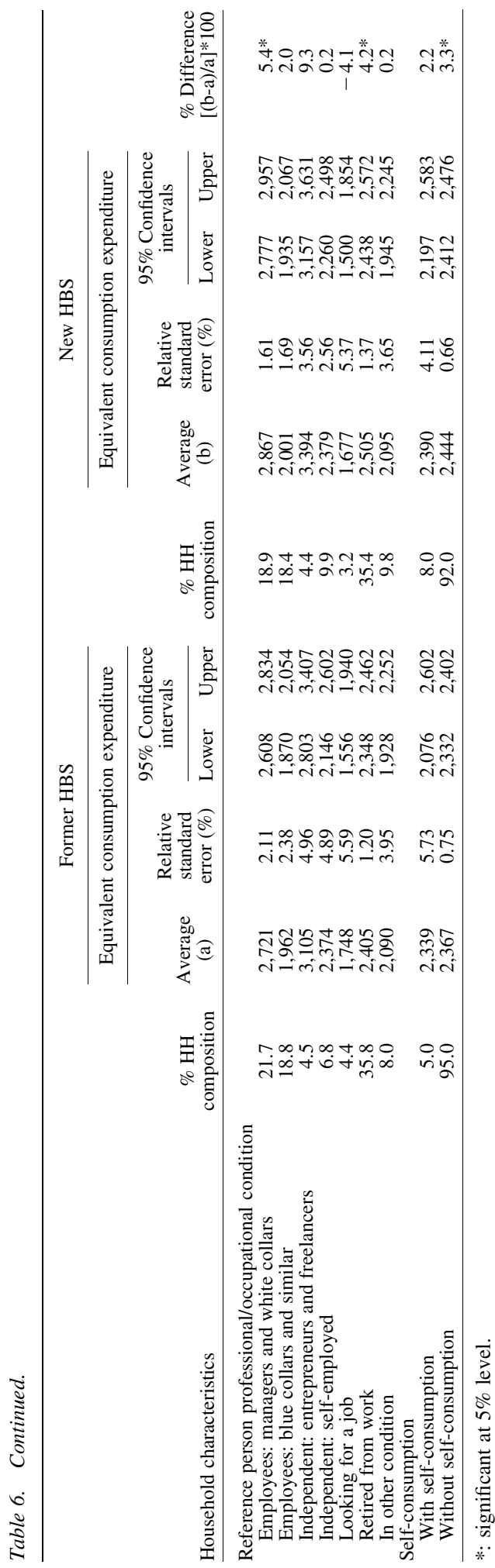




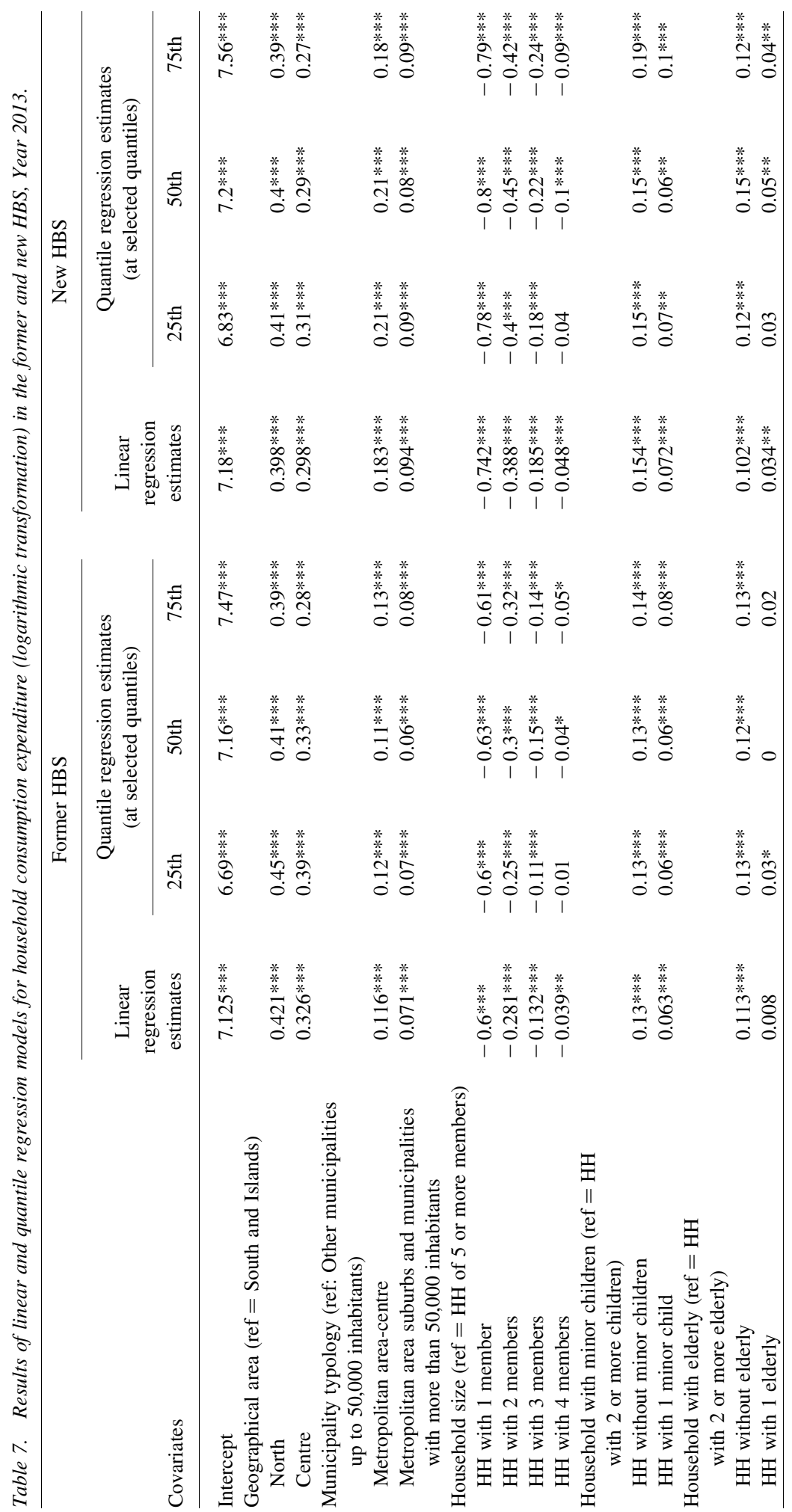




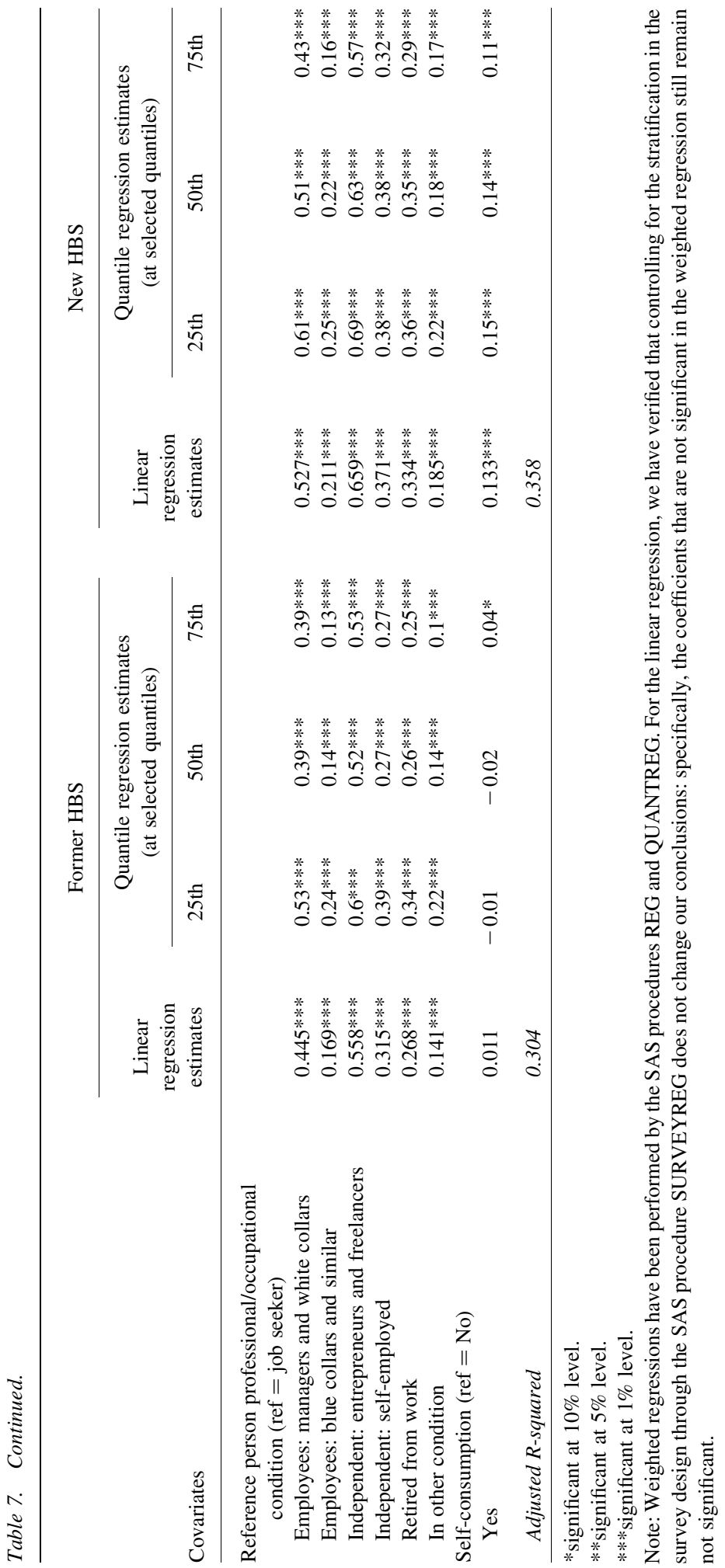




\section{References}

Andreski, P., G. Li, M.Z. Samancioglu, and R. Schoeni. 2014. "Estimates of Annual Consumption Expenditures and Its Major Components in the PSID in Comparison to the CE." American Economic Review 104(5): 132-135. DOI: https://doi.org/10.1257/ aer.104.5.132.

Angrisani, M., A. Kapteyn, and S. Schuh. 2015. "Measuring Household Spending and Payment Habits: The Role of "Typical" and "Specific" Time Frames in Survey Questions." In Improving the Measurement of Consumer Expenditures, edited by C.D. Carroll, T.F. Crossley, and J. Sabelhaus. NBER Book Series Studies in Income and Wealth, 74: 414-440. Chicago: University Press. DOI: https://doi.org/10.7208/chicago/ 9780226194714.003 .0016$.

Bank of Italy. 2018. Annual report for 2017, 124th Financial Year, Rome. Available at: https://www.bancaditalia.it/pubblicazioni/relazione-annuale/2017/en_rel_2017.pdf? language_id=1 (accessed March 2019).

Barrett, G., P. Levell, and K. Milligan. 2015. "A comparison of micro and macro expenditure measures across countries using differing survey methods." In Improving the Measurement of Consumer Expenditures, edited by C.D. Carroll, T.F. Crossley, and J. Sabelhaus. NBER Book Series Studies in Income and Wealth, 74: 263-286. Chicago: University of Chicago Press. DOI: https://doi.org/10.7208/chicago/9780226194714. 003.0010 .

Bee, A., B.D. Meyer, and J.X. Sullivan. 2015. "The validity of consumption data: Are the consumer expenditure interview and diary surveys informative?". In Improving the Measurement of Consumer Expenditures, edited by C.D. Carroll, T.F. Crossley, and J. Sabelhaus. NBER Book Series Studies in Income and Wealth, 74: 204-240. Chicago: University Press. DOI: https://doi.org/10.7208/chicago/9780226194714.003.0008.

Censis. 2012. Crisi: Vivere insieme, vivere meglio. Ricerca Censis-Coldiretti. Centro Studi Investimenti Sociali. Available at: https:/www.coldiretti.it/archivio/il-rapporto-coldiretticensis-crisi-vivere-insieme-vivere-meglio (accessed April 2018).

Cifaldi, G. and A. Neri. 2013. "Asking income and consumption questions in the same survey: what are the risks?". Bank of Italy Economic Working Papers: 908. Available at: https://www.bancaditalia.it/pubblicazioni/temidiscussione/2013/2013-0908/en_tema_ 908.pdf (accessed March 2018).

Commissione di indagine sulla povertà e sull'emarginazione. 1996. "Le misure della povertà in Italia: scale di equivalenza e aspetti demografici.” Presidenza del Consiglio dei Ministri. Roma. Available at: http://sitiarcheologici.lavoro.gov.it/Documents/ Resources/Lavoro/CIES/Scale_equivalenza_1996.pdf (accessed October 2018).

Crossley, T.F. and J.K. Winter. 2015. “Asking Households About Expenditures: What Have We Learned?”. In Improving the Measurement of Consumer Expenditures, edited by C.D. Carroll, T.F. Crossley, and J. Sabelhaus. NBER Book Series Studies in Income and Wealth, 74: 23-50. Chicago: University Press. DOI: https://doi.org/10.7208/ chicago/9780226194714.003.0002.

Eurostat. 2003. Household Budget Surveys in the EU. Methodology and Recommendations for Harmonisation-2003. Methods and Nomenclatures. Luxembourg: Eurostat. 
Available at: http://ec.europa.eu/eurostat/ramon/statmanuals/files/KS-BF-03-003-N-EN.pdf (accessed February 2018).

Eurostat. 2013. COICOP Five-Digit - Structure and Explanatory Notes, Unit B5. Luxembourg. Available at: https://www.dst.dk/ext/4197663288/0/pris/COICOP-pdf (accessed February 2018).

Eurostat. 2015. Household Budget Survey, 2010 Wave. EU Quality report. Luxembourg. Available at: http://ec.europa.eu/eurostat/documents/54431/1966394/2015-04-01_ QualityReport2010.pdf/418a037a-bfbc-486e-9ff7-4b140b543f39 (accessed February 2018).

Eurostat. 2017. "Transmission, processing and publication of HBS 2015 data." Paper presented at the Working group on Income and Living Conditions, Household Budget Survey, 28 September 2017. Luxembourg. Available at: https://slideplayer.com/slide/ 15095624/\#.Xp3JyPTpZQ0.gmail (accessed February 2018).

Freguja, C. and C. Romano, eds. 2014. "La modernizzazione delle tecniche di rilevazione nelle indagini socio-economiche sulle famiglie". Metodi-Letture statistiche Istat Series. ISBN 978-88-458-1806-6. Available at: https://www.istat.it/it/archivio/145721 (accessed March 2018).

Gazzelloni, S., ed. 2006. "La rilevazione sulle forze di lavoro: contenuti, metodologie, organizzazione”. Metodi e Norme Istat Series 32. ISBN 88-458-1357-6. Available at: https://www.istat.it/it/files/2014/06/met_norme_06_32_rilevazione_forze_lavoro.pdf (accessed February 2018).

Gonzalez, M.J. and J.L. Eltinge. 2010. Sensitivity of Inference under Imputation: An Empirical Study. Available at: https://www.researchgate.net/publication/265893889_ Sensitivity_of_Inference_under_Imputation_An_Empirical_Study (accessed April 2018).

Grassi, D. and N. Pannuzi, eds. 2015. "La nuova indagine sulle spese per consumi in Italia”. Metodi-Letture statistiche Istat Series. ISBN 978-88-458-1856-1. Available at: https://www.istat.it/it/archivio/182165 (accessed February 2018).

Istat. 2015. La spesa per consumi delle famiglie. Anno 2014. 8 July 2015. Available at: https://www.istat.it/it/archivio/164313 (accessed February 2018).

Lavallée, P. and J.-F. Beaumont. 2015. "Why We Should Put Some Weight on Weights". Survey Insights: Methods from the Field, Weighting: Practical Issues and 'How to' Approach, Invited article. Available at: https://surveyinsights.org/?p=6255 (accessed March 2019).

Lemmi, A., D. Grassi, A. Masi, N. Pannuzi, and A. Regoli. 2019. "Methodological Choices and Data Quality Issues for Official Poverty Measures: Evidences from Italy". Social Indicators Research 141(1): 299-330. DOI: https://doi.org/10.1007/s11205-018-1841-3.

Mathiowetz, N.A., C. Brown, and J. Bound. 2002. "Measurement Error in Surveys of the Low-Income Population”. In Studies of Welfare Populations: Data Collection and Research Issues, edited by M. Ver Ploeg, R.A. Moffit, and C.F. Citro: 157-194. DC: National Research Council. DOI: https://doi.org/10.17226/10206.

Mulry, M.H, E.M. Nichols, and J.H. Childs. 2016. "A Case Study of Error in Survey Reports of Move Month Using the U.S. Postal Service Change of Address Records" . Survey Methods: Insights from the Field. DOI: https://doi.org/10.13094/SMIF-2016-00004.

Neter, J. and J. Waksberg. 1964. "A Study of Response Errors in Expenditures Data from Household Interviews". Journal of the American Statistical Association 59(305): 18-55. DOI: https://doi.org/10.1080/01621459.1964.10480699. 
Ngandu, N.K., S. Manda, D. Besada, S. Rohde, N.P. Oliphant, and T. Doherty. 2016. "Does adjusting for recall in trend analysis affect coverage estimates for maternal and child health indicators? An analysis of DHS and MICS survey data". Glob Health Action 9. DOI: https://doi.org/10.3402/gha.v9.32408.

OECD. 2013. OECD Framework for Statistics on the Distribution of Household Income, Consumption and Wealth. OECD Publishing. Paris. DOI: https://doi.org/10.1787/ 9789264194830-en.

Osier, G. 2009. "Variance estimation for complex indicators of poverty and inequality using linearization techniques". Survey Research Methods 3(3): 167-195. DOI: https://doi.org/10.18148/srm/2009.v3i3.369.

Polivka, A.E. and S.M. Miller. 1998. "The CPS after the Redesign: Refocusing the Economic Lens Chapter". In Labor Statistics Measurement Issues, edited by John Haltiwanger, Marilyn E. Manser, and Robert Topel, 249-289. Chicago: University of Chicago Press.

Raghunathan, T.E., J.M. Lepkowski, J. van Hoewyk, and P. Solenberger. 2001. "A Multivariate Technique for Multiply Imputing Missing Values Using a Sequence of Regression Models”. Survey Methodology 27(1): 85-95. Available at: https://www150. statcan.gc.ca/n1/en/pub/12-001-x/2001001/article/5857-eng.pdf?st=HUdPxONq (accessed June 2019).

Smith, L.C., O. Dupriez, and N. Troubat. 2014. "Assessment of the Reliability and Relevance of the Food Data Collected in National Household Consumption and Expenditure Surveys". International Household Survey Network Working Paper No. 008. Available at: http://www.ihsn.org/sites/default/files/resources/IHSN_WP008_EN.pdf (accessed April 2018).

UN Statistical Commission. 2018. "Revised Classification of Individual Consumption According to Purpose (COICOP 2018) - Introductory guidelines." Prepared by the Technical Subgroup for the Revision of COICOP (TSG-COICOP), Statistical Commission Background document, Forty-ninth session 6-9 March 2018. Available at: https://unstats.un.org/unsd/statcom/49th-session/documents/BG-Item31-ClassificationE.pdf (accessed February 2018).

Van den Brakel, J., X-M. Zhang, and S.M. Tam. 2017. "Measuring discontinuities due to survey process redesigns". CBS discussion paper 2017/13. Statistics Netherlands. Available at: https://www.cbs.nl/en-gb/background/2017/30/measuring-discontinuitiesdue-to-survey-process-redesigns (accessed February 2018).

Zbikowski, A. and A. Lubich, eds. 2006. "Design and Methodology Current Population Survey U.S. Census Bureau”. Current population Survey Design and Methodology Technical Paper 66. Available at: https://www.census.gov/prod/2006pubs/tp-66.pdf (accessed February 2018).

Zezza, A., C. Carletto, J.L. Fiedler, P. Gennari, and D. Jolliffe. 2017. Food counts. Measuring food consumption and expenditures in household consumption and expenditure surveys (HCES). Introduction to the special issue. Food Policy 72: 1-6. DOI: https://doi.org/10.1016/j.foodpol.2017.08.007.

Received August 2018

Revised October 2019

Accepted January 2020 